Have these statements been refuted? How can they be reconciled with this carbolic-acid fuss? Be it observed that even Dr. Keith does not mention whether he had greater success during the employment of carbolic acid in his ovariotomy cases than during the régime of the oldfashioned, yet notwithstanding good, antiseptics referred. to in his communication.

I hold, further, that as a rule, these medical and surgical sensations are obstructive to the progress of true science, owing to the mental diversion from other and rational treatment, and the necessary time occupied in unlearning.

Let me assure Dr. Keith that I am actuated by no captious, no ungenerous, far less personal, motive in this matter. If he and other high authorities will persist in talking of "Mr. Lister's discoveries," can he find fault if less penetrating intellects inquire, What are they? Where are they to be found? It is true that Mr. Lister's recent prelections on carbolic acid have given our medical school "a name,"-whether olive-branches and laurels have been placed thereby on the chair and memory of John Burns, it is not for me to say.

These, then, are my humble views on this subject, too extended, no doubt; but as I shall not trouble you again unless they are assailed to more purpose, I hope you will pardon the amount of valuable space occupied.

I am, Sir, your obedient servant, Donatid Campbeli Brack.

Glasgow, September 27 th, 1869.

\section{ABORTION - MONGERS.}

To the Editor of THE LANCET.

SIR,-In your observations upon the sentence condemning Timson for procuring abortion, you very justly conclude that this person had no right to any professional title; and you say, "It would be satisfactory were officers of justice to take the trouble to refer to the authorised Medical Register before accepting the claim of every ignorant quack to the honourable titles of the profession."

As I was present during the trial, at the request of the Chief Commissioner of Police, by whom the prosecution was instituted, in order to give evidence as to the intent and effect of the means used by the prisoner, I am able to state that it was perfectly known that Timson had no claim to any professional title. He was described on the Calendar as a "labourer." The solicitors, Messrs. Ellis and Ellis, who instructed the counsel for the prosecution, urged a reference to the Register to show that the prisoner's name was not there. An authenticated copy of the Register was provided for that purpose; but the counsel, Mr. Cooper, who, I believe, is animated by sincere regard for the honour of the medical profession, declined to enter upon this point He saw that his verdict was safe; and knowing that in law it made no difference whether the perpetrator of the crime alleged were a qualified man or not, he, with true forensic tact, preferred to stand where he was, and not to risk raising any fresh point.

Having been frequently called on to consider this question of criminal abortion, perhaps you will afford me this opportunity of urging an important rule in practice upon the attention of the medical profession. The young woman who was the subject of the crime in this instance-as is most commonly the case-went to the house of the abortionmonger, who then and there passed some instrument into the uterus. Now the rule I insist upon is calculated to place this conduct in the widest possible contrast to the practice of the profession. I presume no medical man, even in the case of the clearest necessity for interrupting pregnancy, would perform the operation at his own. house. Apart from every other reason, he would not subject his patient to the obvious dangers attending such a course; and a woman who can walk out of doors cannot be in such urgent case as to require the operation on the spot. It is, therefore, primta facie evidence of ignorance or of crime to perform the operation for the induction of labour under the circumstances proved in the case of Timson. But this would become more clear if it were laid down as an imperative rule, universally and religiously observed by the medical profession, never to perform the operation for the induction of labour except after consultation. This rule received the sanction of Denman and his contemporaries, at the time when the operation was first promulgated. The strict observance of it by us would strike with authoritative condemnation the conduct of those who seek to cover flagitious deeds under the pretext of performing a medical duty. I am, Sir, your obedient servant,

Grosvenor-street, Grosvenor-square, Oct. 4th, 1869. Robert BARnes.

\section{ST. BARTHOLOMEW'S HOSPITAL. To the Editor of THE LANCET.}

SIr,-I feel sure that I cannot have been the only one of Mr. Paget's friends and admirers present at our annual dinner who regretted to hear his eloquence engaged on the relations between the staff of the hospital and its executive body, and the activity with which they have applied themselves to the improvement of the out-patient practice. As you have once already given my plain English a place in your journal, I venture to offer you a few facts bearing on this question.

A long time ago, I believe some six or eight months back, a council consisting of senior members of the staff, and having no official connexion with the Medical School, presented to the Treasurer a scheme for the improvement of the out-patient practice. I am informed, on good authority, that on the 26th July last that gentleman admitted to a deputation, who were endeavouring to settle his difference with the house-surgeons and dressers, that he had not given this document his consideration, or even read it through. Three or four days after the senior members of the staff dispersed for the vacation, and they have only returned to town within about as many days.

These facts speak for themselves, and afford an instance of passiveness on the one hand, and obstructiveness on the other, that are a marvel and a sorrow to me.

I am, Sir, your obedient servant,

\section{FAIR PuAY.}

\section{PARIS.}

(FROMI OUR OWN CORRESPONDENT.)

\section{EXPRBIMENTS WITH CHIORAT.}

M. Demareday, whose recent experiments on chloral $I$ mentioned in my last letter but one, has continued his researches, and last week he informed the Academy of Sciences of the novel results he has obtained. He has been trying chloral, administered internally, in combination with syrup of balsam of tolu. The compound was administered to twenty patients in doses varying from one to five grammes of chloral. M. Demarquay summed up his communication as follows:-

1. Chloral has a well-marked hypnotic action, especially in weak and debilitated patients.

2. The duration of its action is in direct proportion with the feebleness of the patients.

3. The sleep which it brings on is generally calm, and is accompanied by restlessness only when the patients are suffering from intense pain. This induces one to employ it in diseases where it is desired especially to induce sleep and muscular resolution.

4. Lastly, this remedy may be employed in high doses, since no ill effects result from it when administered in doses of from one to five grammes.

\section{SCIENTIFIC ASCENT OF MONT BLANC.}

Dr. Lortat, of Lyons, has just made known the results of two ascents of Mont Blanc, which he had performed on the 17th and 27 th of August last. He had providec himself with the necessary iustruments for studying the physiological phenomena which are observed on moun tain heights, and, amongst others, had taken with him several special thermometers, Bergeon and Kastus's opno graph, Marey's sphygmograph, \&c. Thus he has been abl 